\title{
Visual explanations of first order differential equations
}

\author{
Daniel Raviv, Ph.D. \\ Florida Atlantic University, USA, ravivd@fau.edu
}

\begin{abstract}
In order to adapt to students' learning preferences and styles, efforts must be made to include relevance of the material to daily life experiences, preferably in easy-to-comprehend, visual, and intuitive ways. This is most relevant in math courses that are usually taught with little or no connection to other disciplines, and in particular engineering. This paper focuses on introducing first order differential equation and time constant of first order system using intuitive examples such as cell phone charging, cooling rates of hot coffee, diffusion, and time responses of different vehicles.
\end{abstract}

Keywords - Visual, intuitive, learning, math, first order differential equation.

\section{INTRODUCTION}

This paper focuses on visual and intuitive experiencebased explanations of first order differential equation. The concept is connected by analogy to real-life examples that are meant to provide additional material for introductory purposes only, to allow students to see the relevance of math to their daily life. The examples intentionally use almost no equations. The sets of multi-faceted concept-based examples that are illustrated in this paper are meant to allow learners to not only recognize and appreciate the relevance of math to everyday life, but also tap on different learning styles and keep learners engaged, thereby allowing for multiple and diverse ways of comprehension.

The material is referred to as work in progress and is to be shared and discussed with multiple audiences. When these and many other examples were used, students have demonstrated better, clearer understanding of difficult concepts, and praised the approach. Even though this was not an official assessment, based on similar experience that was gained and assessed by the author in other engineering and science related subjects (Control Systems, Digital Signal Processing, Computer Algorithms, and Physics), it is believed that the approach has a great potential. Students not only have commended the approach, but they have demonstrated its effectiveness.

The rational for this this work stems from observations that the current generation of students learn differently: less textbook-reliance, and more dependence on web-based explanations, such as short videos, animations, and demonstrations. When it comes to concept comprehension, students repeatedly miss the Aha! moment, and ask for more hands-on, experiential, visual, intuitive, fun (e.g., game-based), and tech-based, web-based information.

This is not new. For example, Tyler DeWitt [1] recognized this problem and taught isotopes to high school students using analogy to similar cars with minor changes to illustrate that isotopes are basically the same atom, i.e., have the same number of protons and electrons with varying number of neutrons. By focusing on calculus there are some books that include visual explanations (see for example references [2-10]). Of a special interest is the work by Apostol and Mamikon from Caltech $[11,12]$. They were able to explain integration of some functions without the need for mathematical formulas. The author of this paper published papers on this topic [13-20] in addition to STEM related books [21,22].

This work is part of a multi-modal integrated project aimed at understanding concepts in STEM. The approach is meant to help both teachers and students, thereby allowing for more innovative teaching and comprehension-based learning. The project is catered towards appealing to learners in visual, intuitive, and interactive/engaging means. It uses daily-life and liferelevant experiences, as well as different STEM/STEAM examples and activities. The project targets a broad understanding and appreciation of

Digital Object Identifier (DOI): http://dx.doi.org/10.18687/LACCEI2018.1.1.211

ISBN: 978-0-9993443-1-6

ISSN: $2414-6390$

basic concepts in STEM, currently involving

16 $^{\text {th }}$ LACCEI International Multi-Conference for Engineering, Education, and Technology: "Innovation in 
Physics/Mechanics, Calculus, Statics, Control Systems, Digital Signal Processing (DSP), Probability, Estimation, and Computer Algorithms. Though the material can be used by teachers and learners in classroom settings, it is primarily designed to (eventually) be web-based, targeting those who prefer self-paced self-learning friendly environments. Simply put, the project is principally designed for a learner-centered e-based environment, making it ready for large scale dissemination. Examples of calculus concepts that the author and his team plan to develop and integrate include: (a) games, (b) puzzles and teasers, (c) animations, (d) visual and intuitive daily-experiences-based examples, (e) movies and short video clips, (f) demonstrations, (g) hands-on activities (including those based on virtual reality and augmented reality), (h) teaming and communication exercises, (i) small-scale inquiry-based research, (j) presentations, and peer-based teaching/learning, (k) visual click-based e-book, (l) community and social engagement, and (m) challenges beyond the basics.

\section{FIRST ORDER DIFFERENTIAL EQUATION EXAMPLES}

The following is a set of examples that shows first order systems and behaviors. We show only a few, but obviously there are many other examples from many disciplines.

\subsection{Cell phone battery example}

The voltage function during the battery charging process of a mobile phone is illustrated in Figure 1. It is basically a "resistor capacitor" (RC) circuit that can be described using first order differential equation.

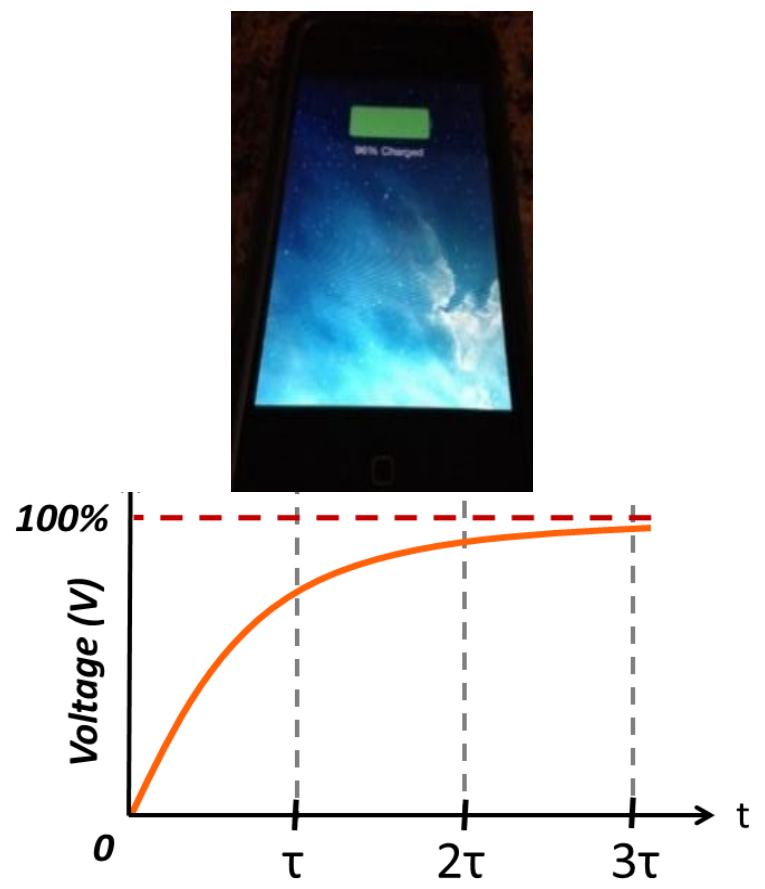

Figure 1: Charging a mobile phone - first order system

Let's observe (Figure 2) different initial charging values and at different stages of the battery's life. Say someone wants to charge his or her phone in three phases, unplugging the charger and quickly plugging it back in, stopping at a certain time, say at the so called time constant $\tau$, and its multiples, as depicted here. This is an experience-based example: We all know that cell phone charges faster in the beginning and slower later: the change (the derivative) is different at each point in time.

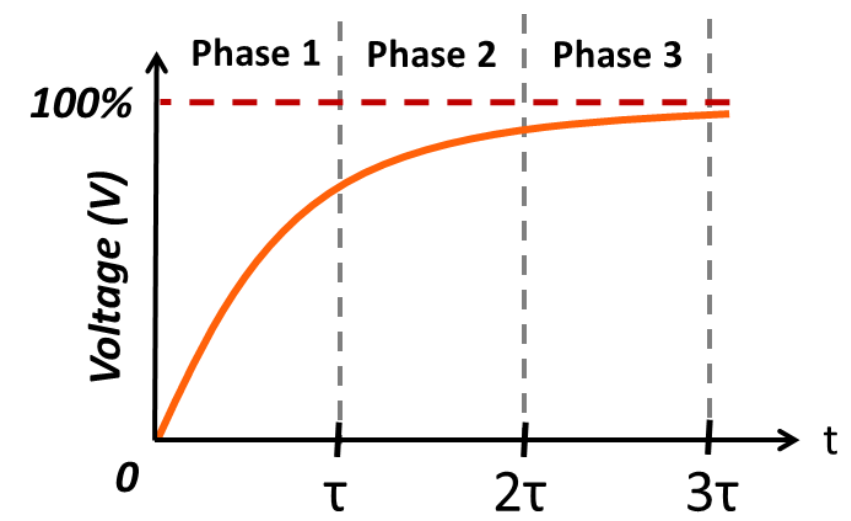

Figure 2: Charging mobile phone in three steps

16 $^{\text {th }}$ LACCEI International Multi-Conference for Engineering, Education, and Technology: "Innovation in Education and Inclusion”, 18-20 July 2018, Lima, Peru. 
The charging is broken down to three phases look like the following (Figure 3). Note the different derivatives of the graphs at different points in time: they are instants of exponentially decaying function.

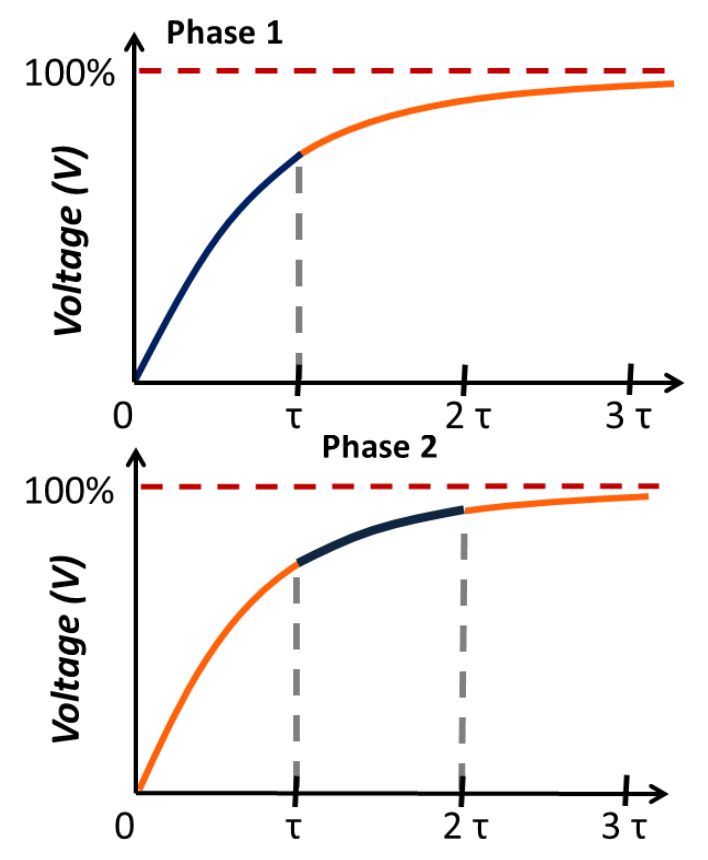

Phase 3

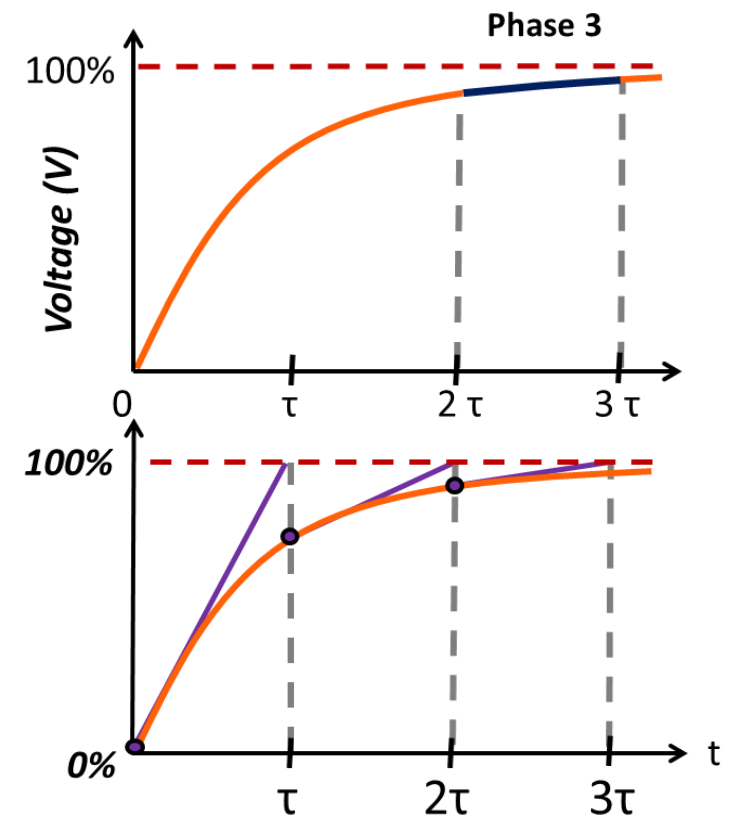

Figure 3: Charging mobile phone in three steps to compute the area under the graph without using integration!

\subsection{Coffee cooling example}

Cooling rate of coffee is proportional to the difference between the coffee temperature and the room temperatures. The following is a brain teaser (followed by a solution) that can help in understanding the concept.

\section{Puzzler}

\section{Question:}

One day, two brothers had a dispute. The first brother, Joe, claimed that coffee stays hotter if one pours cold creamer ten minutes after initially pouring the coffee. The second brother, Moe, claimed that it would stay hotter after 10 minutes if cold creamer is added right away. Based on what you know about time constants: which brother is correct?

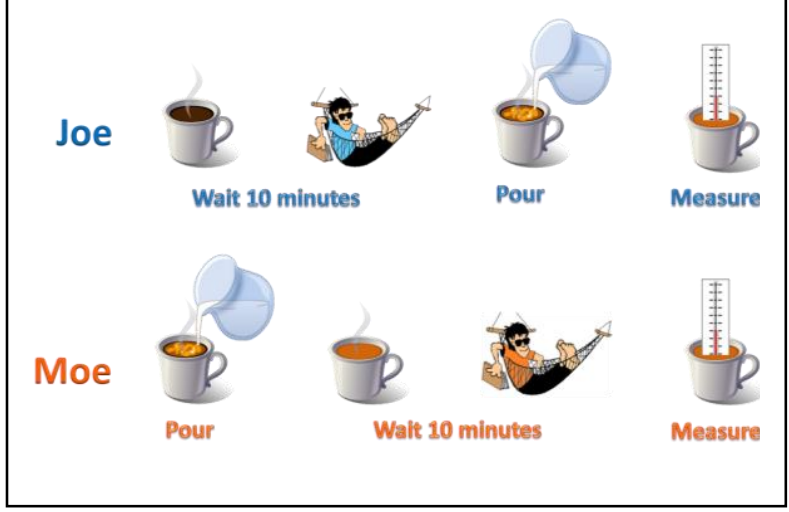

It should be noted that at any point in time the tangent line of the graph touches the line of the final value exactly $\tau$ seconds later. This property of a first order system was used by Mamikon and Apostol [11]

$16^{\text {th }}$ LACCEI International Multi-Conference for Engineering, Education, and Technology: "Innovation in Education and Inclusion”, 18-20 July 2018, Lima, Peru. 


\section{Answer:}

Since the first cup of coffee starts at a hotter temperature, the initial slope is greater. This causes the temperature of the first cup to decay more rapidly. Therefore, when Joe adds the creamer to the first cup, the temperature spike drops it below the temperature of cup two. This makes Moe correct. Simply put, pouring cold creamer first and then waiting guarantees hotter coffee. This is depicted in the following qualitative graph.

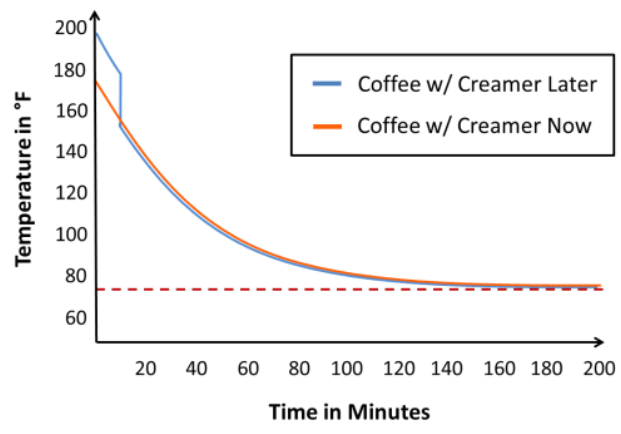

Zooming in on the initial time:

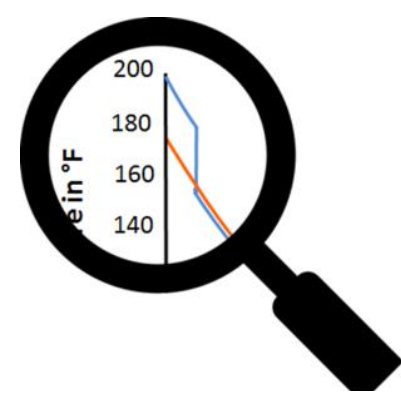

2.3 Toilet mechanism example (refer to Figure 4)

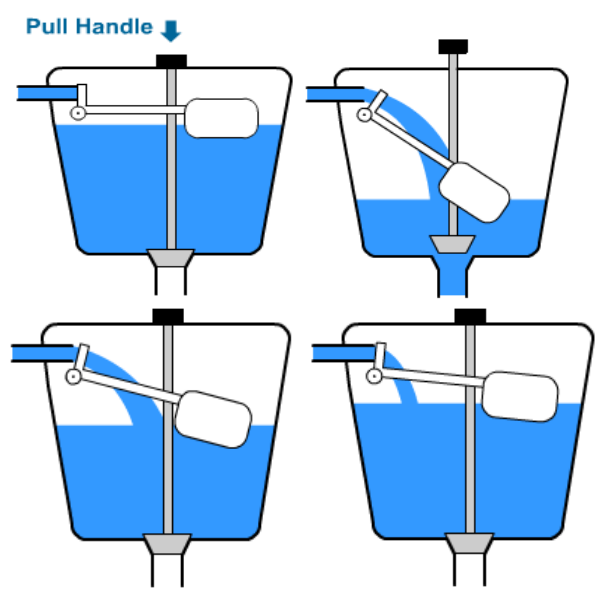

Figure 4: Visualization of toilet mechanism - a mechanical first order system

The water level after flushing the toilet rises following a response that is very similar to a step response of first order system (i.e., the change in water level is proportional to the difference between the actual water level and the max water level, due to the continuous decrease in water flow through the valve).

\subsection{Diffusion example}

Diffusion occurs at an exponential rate. This is when molecules from a region of high concentration move to a region of lower concentration. It occurs naturally as molecules randomly bounce off each other, and they are more likely to fill open space then continue to bounce off each other in close quarters. For example, assume there are two compartments separated by a wall, one filled with gas molecules and the other is just a vacuum (Figure 5).
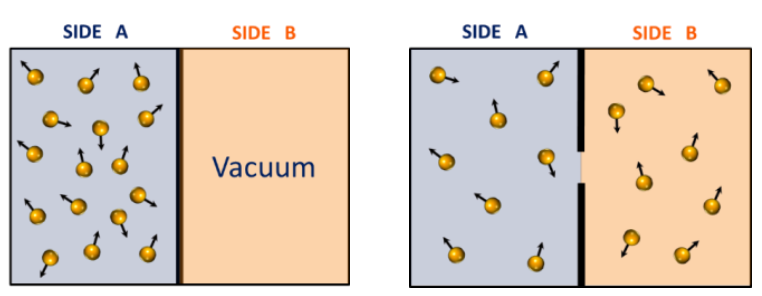

Figure 5: Diffusion: before and after

Several factors affect the diffusion process, including the initial concentration/pressure, the ongoing pressure difference between the two chambers, and

$16^{\text {th }}$ LACCEI International Multi-Conference for Engineering, Education, and Technology: "Innovation in Education and Inclusion”, 18-20 July 2018, Lima, Peru. 
the size of the opening. Eventually the concentrations of molecules in the two chambers will reach the same value (Figure 6). It happens at an exponentially decaying rate.

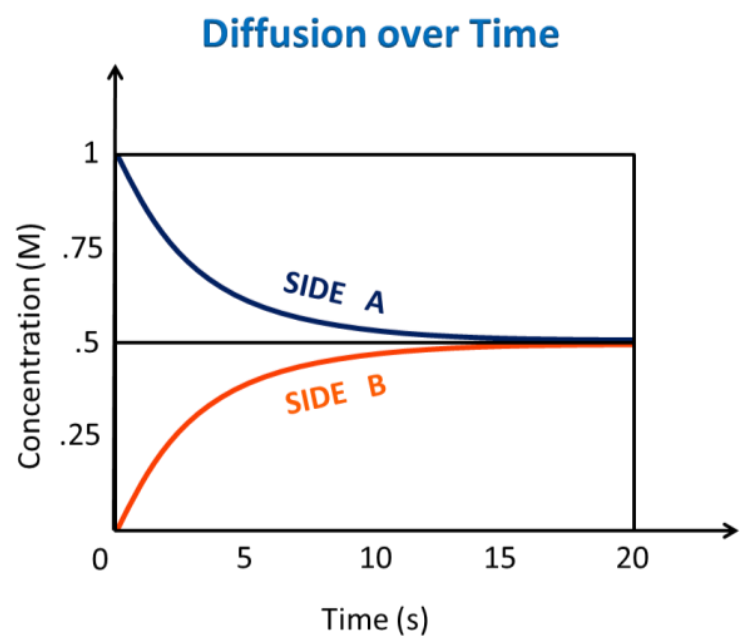

Figure 6: Diffusion: concentration as a function of time

\subsection{Car dynamics example}
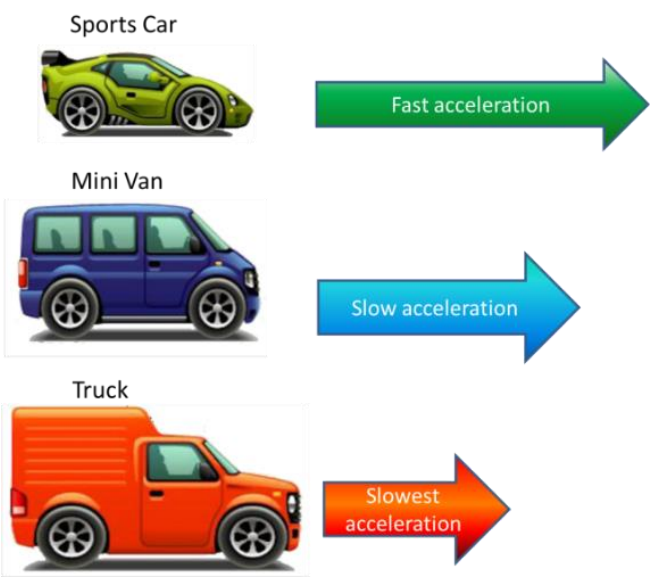

Time Constants

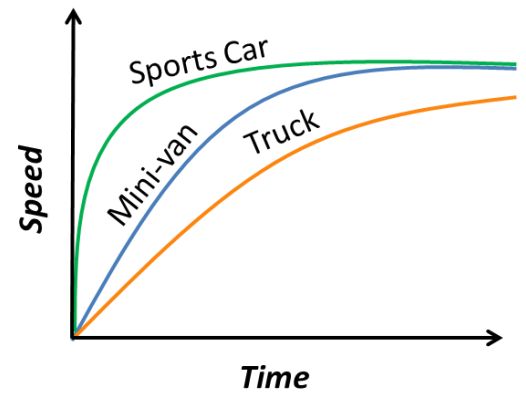

Figure 7: Comparing " 0 to 60 " behaviors of three vehicles

$1^{\text {th }}$ LACCEI International Multi-Conference for Engineering, Education, and Technology: "Innovation in
A first order system whose input is a "step", in the case of the car, means pushing the gas pedal all the way to the mat will qualitatively respond as shown in different colors, green for sports car, blue for mini-van and orange for truck. This is a behavior that is similar to a first order system (Figure 7).

\subsection{DC motor example (refer to Figure 8)}

A DC motor has a dominant (slow) time constant, aka the mechanical time constant. Because of this constant, the response to a step function can be approximated by a first order linear differential equation. (Note that the integration relation between $\omega$ and $\theta$ of a DC motor is always pure integration and is independent of the time constant.)

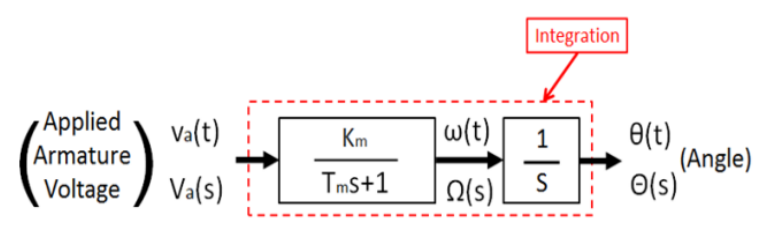

Figure 8: DC motor: effect of mechanical time constant

Note the angular speed $\omega(t)$ and the angular position $\theta(t)$ of the motor as a function of time. When an armature voltage is applied (as a step function), the angular speed, $\omega(t)$, first increases quickly then plateaus to a constant value. On the other hand, the angular position of the motors, $\theta(t)$, continues to increase. This makes sense because as the motor keeps spinning with a constant angular speed, the motor position will keep increasing as well.

\section{CONCLUSION}

The illustrated sets of examples attempt to introduce first order differential equation using relevant analogy-based examples. The idea is to introduce math-less visual and intuitive examples so that students understand and comprehend basic concepts and their importance and relevance. It is important to emphasize that the material presented in this paper is meant to be add-ons to existing calculus textbooks, and is not meant to suggest competition, Education and Inclusion”, 18-20 July 2018, Lima, Peru. 
modifications or replacement of existing textbooks. The presented material is referred to as work in progress and can be shared and discussed with multiple audiences. We hope that the reader will use some of the examples, as well as suggesting new ideas and/or sharing his/her own.

\section{ACKNOWLEDGEMENTS}

The author thanks Venturewell.org (formerly NCIIA.org), for the support of the development of innovative and entrepreneurial teaching and learning methods, and Michael R. Levine and Last Best Chance, LLC, for the continuous support.

Special thanks to Professors Moshe Barak, Miri Barak, Nancy Romance, and Nahum Shimkin for the very fruitful discussions on enhancing the teaching and learning of concepts in STEM.

Special thanks to George Roskovich and Pamela Noguera for providing some of the excellent illustrations. The Center for Writing at FAU provided very valuable feedback as well.

\section{REFERENCES}

[1]

https://www.youtube.com/watch?v=EboWeWmh5Pg

[2] Adams, Colin Conrad. Zombies \& Calculus. State- Massachusets: Princeton, 2014. Print.

[3] Amdahl, Kenn, and Jim Loats. Calculus for Cats. Broomfield, CO: Clearwater Pub., 2001. Print.

[4] Ghrist, Robert. Funny Little Calculus Text. U of Pennsylvania, 2012. Print.

[5] Herge" The Calculus Affair: The Adventures of Tintin. London: Methuen Children's, 1992. Print.

[6] Kelley, W. The Complete Idiot's Guide to Calculus, 2nd Edition. S.1.: DK, 2006. Print.

[7] Pickover, Clifford A. Calculus and Pizza: A Cookbook for the Hungry Mind. Hoboken, NJ: John Wiley, 2003.

$16^{\text {th }}$ LACCEI International Multi-Conference for Engineering, Education, and Technology: "Innovation in
[8] Averbach, Bonnie, and Orin Chein.Problem Solving through Recreational Mathematics. Mineola, N.Y.: Dover Publications, 2000.

[9] Azad, Kalid. Math, Better Explained, 2014.

[10] Fernandez, Oscar E. Everyday Calculus: Discovering the Hidden Math All around Us. Princeton: Princeton UP, 2014.

[11] Tom Apostol, A Visual Approach to Calculus Problems, ENGINEERING \& SCIENCE N O . 3 2000

http://www.mamikon.com/VisualCalc.pdf

[12] www.mamikon.com

[13] D. Raviv, P. Reyes and J. Baker, "A Comprehensive Step-by-Step Approach for Introducing Design of Control Systems," ASEE National Conference, Columbus, Ohio, June 2017.

[14] D. Raviv, and J. Jimenez, "A Visual, Intuitive, and Experienced-Based Approach to Explaining Stability of Control Systems," ASEE National Conference, Columbus, Ohio, June 2017.

[15] D. Raviv, L. Gloria, Using Puzzles for Teaching and Learning Concepts in Control Systems," ASEE Conference, New Orleans, June 2016.

[16] D. Raviv, P. Benedict Reyes, and G. Roskovich, A Visual and Intuitive Approach to Explaining Digitized Controllers," ASEE Conference, New Orleans, June 2016.

[17] D. Raviv and J. Ramirez, "Experience-Based Approach for Teaching and Learning Concepts in Digital Signal Processing," ASEE National Conference, Seattle, WA, June 2015.

[18] D.Raviv, Y. Nakagawa and G. Roskovich, "A Visual and Engaging Approach to Learning Computer Algorithms," ASEE National Conference, Indianapolis, Indiana, June 2014.

[19] D.Raviv and G. Roskovich, An intuitive approach to teaching key concepts in Control Systems, ASEE Conference, Indianapolis, Indiana, June 2014. Education and Inclusion", 18-20 July 2018, Lima, Peru. 
[20] D.Raviv and G. Roskovich, " An Alternative Method to Teaching Design of Control Systems," LACCEI, Latin American and Caribbean Engineering Institutions, Guayaquil, Ecuador, July 22-24, 2014.

[21] D. Raviv and Megan Geiger, Math-less Physics! A Visual Guide to Understanding Newton's Laws of Motion, Create Space Publishers, 2016.

[22] D. Raviv and G. Roskovich, Understood! A Visual and Intuitive Approach to Teaching and Learning Control Systems: Part 1, Create Space Publishers, 2014.

$16^{\text {th }}$ LACCEI International Multi-Conference for Engineering, Education, and Technology: "Innovation in Education and Inclusion", 18-20 July 2018, Lima, Peru. 